\title{
Special Issue Introduction: The Meaning and Measurement of Thriving: A View of the Issues
}

\author{
Richard M. Lerner • Alexander von Eye • \\ Jacqueline V. Lerner · Selva Lewin-Bizan • \\ Edmond P. Bowers
}

Published online: 13 April 2010

(C) Springer Science+Business Media, LLC 2010

\begin{abstract}
We introduce this special issue on the foundations and functions of adolescent thriving by summarizing the developmental systems theory-based, positive youth development (PYD) perspective. The PYD perspective frames much of contemporary research about health and positive development across the adolescent period and, more specifically, frames the 4-H Study of PYD, the data set from which the empirical work in this special issue is drawn. We discuss the different ways in which the articles in this special issue elucidate different facets of the PYD perspective. In addition, we summarize the implications of this research for future scholarship and for applications aimed at improving the life chances of diverse adolescents.
\end{abstract}

Keywords Developmental systems theory - Plasticity · 4-H Study · Positive youth development

\section{Introduction}

Within the contemporary study of adolescence, the cuttingedge of research is framed by relational, developmental systems models that focus on the links between individual and context that are associated with diverse (positive and

R. M. Lerner $(\bowtie) \cdot$ S. Lewin-Bizan · E. P. Bowers Institute for Applied Research in Youth Development, Tufts University, 305 Lincoln Filene, Medford, MA 02155, USA

e-mail: richard.lerner@tufts.edu; iaryd.pubs@gmail.com

A. von Eye

Michigan State University, East Lansing, MI, USA

J. V. Lerner

Lynch School of Education, Boston College, Chestnut Hill, MA, USA problematic) pathways across the second decade of life, i.e., the "adolescent decade" (Lerner and Steinberg 2009). Developmental systems models emphasize that the basic process of adolescent development involves mutually influential relations between the developing individual and the multiple levels of his/her changing context. These bidirectional relations may be represented as individual $\leftarrow \rightarrow$ context relations. These relations regulate the course of development (i.e., its pace, direction, and outcomes). When individual $\leftarrow \rightarrow$ context relations benefit both the person and his ecology, these developmental regulations may be termed "adaptive" (Brandtstädter 1998, 1999).

History, or temporality, is part of the ecology of human development that is integrated with the individual through developmental regulations. As such, there is always change and, as well, at least some potential for systematic change (i.e., for plasticity), across the life span (Baltes et al. 2006; Lerner 1984). Multiple dimensions of profound changes are prototypic of the adolescent period, involving levels of organization ranging from the physical and physiological, through the cognitive, emotional, and behavioral, and to the social relational and institutional. Plasticity represents a fundamental strength of the adolescent period (Lerner 2005, 2009), in that it reflects the potential that systematic changes may result in more positive functioning. Indeed, if adaptive developmental regulations emerge or can be fostered between the plastic, developing young person and features of his context (e.g., the structure and function of his/her family, school, peer group, and community), then the likelihood will be increased that youth may thrive (that is, manifest healthy, positive developmental changes) across the adolescent decade.

In short, predicated on developmental systems theory models, the links among the ideas of plasticity, adaptive developmental regulations, and thriving suggest that all 
young people have strengths that may be capitalized on to promote thriving across the adolescent years. For instance, one example of the emerging strengths of adolescents is their ability to contribute intentionally to the adaptive developmental regulations with their context (Gestsdóttir and Lerner 2008). Such intentional self regulation may involve the selection of positive goals (e.g., drawing from the context the resources needed for adaptive functioning), using cognitive and behavioral skills (such as executive functioning or resource recruitment) to optimize the chances of actualizing ones purposes and, when goals are blocked or when initial attempts at optimization fail, possessing the capacity to compensate effectively (Baltes and Baltes 1990; Freund and Baltes 2002).

Simply, because of the convergence of the ideas of plasticity, adaptive developmental regulations, and thriving it is possible to assert that all young people constitute "resources to be developed" (Roth and Brooks-Gunn 2003a, b). Increasingly, this strength-based view of adolescents has become the predominant conceptual lens through which youth are studied within the United States (e.g., Lerner et al. 2009a) and internationally (e.g., Gestsdóttir and Lerner 2007a; Silbereisen and Lerner 2007). Labeled the "Positive Youth Development" (PYD) perspective (Damon 2004; Lerner 2005, 2007, 2009), this view of adolescent development seeks to identify the individual and ecological bases of thriving among diverse youth and to apply this knowledge in policies and programs designed to promote PYD.

Research pertinent to the PYD perspective has become a more prominent part of the literature of adolescent development across the first decade of the twenty-first century (e.g., Benson 2006; Damon 2004; Larson 2000; Lerner et al. 2005a, b; Lerner et al. 2009a, b; Silbereisen and Lerner 2007). The empirical findings from this work have impacted both the nature of the developmental systems theoretical, or structural, model framing the PYD perspective (e.g., Phelps et al. 2007) and the measurement model used to operationalize the structural model (e.g., Gestsdóttir and Lerner 2007b; Phelps et al. 2009). In fact, past research pertinent to the PYD perspective has underscored the mutual dependencies between theory and method in developmental science (Lerner 2002). Accordingly, while past scholarship pertinent to the PYD perspective about the nature of thriving in adolescence has contributed enormously to the clarification or refinement of this approach to understanding adolescence, this same work has pointed to additional research that needs to be conducted for further progress to be made in regard to understanding the meaning and measurement of thriving in adolescence.

This goal of this special issue is to contribute to this progress. Using data from a large longitudinal investigation, the 4-H Study of Positive Youth Development (PYD) (e.g.,
Lerner et al. 2005a, b; Phelps et al. 2009), the articles in this special issue seek to enhance theory-predicated understanding of the meaning and measurement of thriving across the adolescent period. Accordingly, to explain how the research reports and commentaries included in this special issue may address this goal, it is useful to discuss first the assumptions and features of the PYD perspective and, in turn, to note the status of the knowledge base pertinent to this approach to the study of thriving development among adolescents. This discussion will then enable us to note the ways in which the research presented in this special issue may contribute to this knowledge base. Here, we will present both an overview of the 4-H Study of PYD and of the research drawn from it for this special issue. Finally, given that a fundamental goal of the PYD perspective is to apply research to enhance youth development, we will discuss the importance of the commentaries about the present research that are provided in this special issue by colleagues from the practitioner and policy communities.

\section{The PYD Perspective: An Overview}

The PYD perspective stands as a conceptual alternative to the long-held deficit models of the adolescent developmental period (Lerner 2009; Lerner and Steinberg 2009). As such, the PYD perspective provides a rationale for how a strength-based conception of youth may provide, on the one hand, a revised agenda for research about adolescent development and, on the other hand, a different focus for policies and programs aimed at enhancing the life chances of diverse young people.

Instead of searching for the conditions that may decrease problem behaviors or prevent problems from occurring, the PYD perspective broadens the scope of research to include an assessment of the individual $\leftarrow \rightarrow$ context relations that promote thriving across adolescence and that, as well, may have a preventive effect. From this perspective, thriving in adolescence is not seen as the absence of problems (i.e., thriving is not conceived as the absence of bullying, drinking, unsafe sex, school failure, or substance abuse, etc.). Instead, thriving is seen as the growth of attributes that mark a flourishing, healthy young person, e.g., the characteristics termed the "Five Cs" of PYD-competence, confidence, character, connection, and caring (Eccles and Gootman 2002; Lerner et al. 2005a, b; Roth and Brooks-Gunn 2003a, b) and youth contributions to self, family, community, and civil society (Lerner et al. 2005a, b; Lerner et al. 2007).

Accordingly, the PYD perspective suggests that policies should be directed not only to problem reduction or prevention but, as well, to fostering conditions that promote such attributes of thriving. Examples here may include 
providing funding for after school programs that are aimed at promoting positive development or for the recruitment and training of youth mentors. At the same time, the perspective suggests that practitioners should identify the actions needed to provide youth with the individual $\leftarrow \rightarrow$ context relations that place them on a thriving trajectory across adolescence. These actions involve positive and sustained adult-youth relations, life skills building opportunities, and opportunities for youth participation in, and leadership of, valued family, school, and community activities (i.e., actions that are termed by Lerner 2004, as the "Big 3" attributes of effective youth-serving programs).

As implied earlier in this article, the key hypothesis tested in the PYD perspective is that if the strengths of youth (e.g., a young person's cognitive, emotional, and behavioral engagement with the school context, having the "virtue" of hope for the future, or possession of the intentional self-regulation skills of Selection [S], Optimization [O], and Compensation [C]) can be aligned with the resources for positive growth found in families, schools, and communities -for instance, the capacities of adults to provide for young people a nurturing, positive milieu in which their strengths may be enhanced and positively directed (e.g., DuBois and Rhodes 2006; Karcher et al. 2002; Rhodes and Lowe 2009)—-then young people's healthy development may be optimized (Lerner 2004). In addition, given that positively developing youth should be involved in adaptive developmental regulations, that is, mutually beneficial individual $\leftarrow \rightarrow$ context relations, then a thriving young person should act to contribute to the context that is benefiting him or her. In other words, positive development rests on mutually beneficial relations between the adolescent and his/her ecology and, as such, thriving youth should be positively engaged with and act to enhance their world. It is useful to treat theses cores idea within the PYD perspective within a discussion of the origins of the PYD perspective and, in turn, of the key questions addressed by researchers testing these core ideas.

\section{Origins of the PYD Perspective}

As discussed elsewhere, (e.g., Lerner 2009; Lerner et al. 2010a; Lerner and Steinberg 2009) the roots of the PYD perspective are found in the work of comparative psychologists (e.g., Gottlieb et al. 2006; Schneirla 1957) and biologists (e.g., Novikoff 1945a, b; von Bertalanffy 1933) who had been studying the plasticity of developmental processes that arose from the "fusion" (i.e., the reciprocally influential, systematic integration; Tobach and Greenberg 1984) of biological and contextual levels of organization. The ideas of fusion and of plasticity derive from what we have noted is the cutting-edge focus of contemporary, developmental theory-on the relational developmental system, that is, on the mutually influential relations between the developing individual and his/her ecology (Lerner 2006; Overton 2006, 2010b). These relations involve links between the neurological (e.g., brain) and psychological (e.g., cognitive, emotional, and motivational) facets of the person and the features of his/her natural and designed ecology (e.g., the family, school, and the institutions of civil society), the physical setting, and, ultimately, history. We have explained already that, given that history (temporality) is an "arrow" that cuts through all levels that are integrated (fused) within the relational, developmental system, there is always a potential for systematic change ("plasticity") in the behavior and development of the individual.

As noted, the importance of ideas about multiple levels of organization (those within the individual, such as physiology or cognition and those in the ecology, such as the family, educational institutions, and historical events) acting together to shape the nature and positive or negative direction of development across life arose in the study of biology and of non-human species (e.g., Gottlieb et al. 2006; Tobach and Schneirla 1968). However, these ideas began to impact the human developmental sciences in the 1970s (Cairns and Cairns 2006; Gottlieb et al. 2006; Lerner 2002, 2006; Overton 2006). Examples of this influence are the theoretical papers by Overton (1973) and by Lerner (1978) that discussed the nature-nurture controversy. These authors argued that the debate could be resolved by taking an integrative theoretical perspective about nature (e.g., genetic) and nurture (e.g., socialization, education) influences on human development.

These discussions about the systemic relations among variables from all levels of organization involving organisms (individuals) and their physical and social world have resulted in the last several decades in the elaboration of both relational, developmental systems theories of human development (Overton 2010b) and, more specifically, in the strength-based, PYD view of adolescence. It is useful to discuss the key ideas found within the PYD perspective and to note their empirical status.

\section{Components of the PYD Perspective}

Beginning in the early 1990s, and burgeoning in the first decade of the twenty-first century, a new vision and vocabulary for discussing young people has emerged (e.g., see Lerner et al. 2009a, b; Lerner and Steinberg 2009; Lerner et al. 2010b, for discussion). These innovations that characterize the PYD perspective were propelled as well by the increasingly collaborative contributions of researchers focused on the second decade of life (e.g., Benson et al. 2006; Damon 2004; Lerner 2004), practitioners in the field 
of youth development (e.g., Floyd and McKenna 2003; Pittman et al. 2001), and policy makers concerned with improving the life chances of diverse youth and their families (e.g., Cummings 2003; Gore 2003). Indeed, the PYD perspective may be unique among major conceptual models within the developmental science of adolescence in that its genesis and continued progress involves the integration of research and practice, a "tradition" continued in the present special issue by the commentaries provided by Floyd and by Porter.

The interests of researchers and practitioners converged in the formulation of the PYD perspective as a set of ideas that involved two key hypotheses (e.g., see Lerner 2009; Lerner et al. 2010b, for discussion). Each hypothesis is associated with two subsidiary hypotheses. The first hypothesis pertains to the structure of PYD. The second focuses on the relations between individuals and contexts that, within developmental systems models, provide the basis of human development.

\section{Hypothesis 1. PYD is Comprised of Five Cs}

Based on both the experiences of practitioners and on reviews of the adolescent development literature (Eccles and Gootman 2002; Lerner 2004; Roth and Brooks-Gunn 2003a, b), the above noted Five Cs were hypothesized as a way of conceptualizing PYD (and of integrating all the separate indicators of it, such as academic achievement or self esteem). The definitions of these $\mathrm{Cs}$ are presented in Table 1 .

Table 1 Definitions of the Five Cs of positive youth development

\begin{tabular}{ll}
\hline C & Definition \\
\hline Competence & $\begin{array}{c}\text { Positive view of one's actions in domain specific areas } \\
\text { including social, academic, cognitive, and vocational. } \\
\text { Social competence pertains to interpersonal skills } \\
\text { (e.g., conflict resolution). Cognitive competence } \\
\text { pertains to cognitive abilities (e.g., decision making). } \\
\text { School grades, attendance, and test scores are part of } \\
\text { academic competence. Vocational competence } \\
\text { involves work habits and career choice explorations, } \\
\text { including entrepreneurship. }\end{array}$ \\
Confidence & $\begin{array}{c}\text { An internal sense of overall positive self-worth and } \\
\text { self-efficacy; one's global self-regard, as opposed to } \\
\text { domain specific beliefs. }\end{array}$ \\
Connection & $\begin{array}{c}\text { Positive bonds with people and institutions that are } \\
\text { reflected in bidirectional exchanges between the } \\
\text { individual and peers, family, school, and community } \\
\text { in which both parties contribute to the relationship. }\end{array}$ \\
Character $\quad \begin{array}{l}\text { Respect for societal and cultural rules, possession of } \\
\text { standards for correct behaviors, a sense of right and } \\
\text { Wrong (morality), and integrity. }\end{array}$ & A sense of sympathy and empathy for others.
\end{tabular}

Note: Derived from Lerner et al. (2005b) and Roth and Brooks-Gunn (2003a)
These Five Cs were linked to the positive outcomes of youth development programs reported by Roth and BrooksGunn (2003a, b). In addition, these "Cs" are prominent terms used by practitioners, adolescents involved in youth development programs, and the parents of these adolescents in describing the characteristics of a "thriving youth" (King et al. 2005).

A hypothesis subsidiary to the postulation of the "Five Cs" as a means to measure (operationalize) PYD is that, when a young person manifests the Cs across time (when the youth is thriving), he or she will be on a life trajectory towards an "idealized adulthood" (Csikszentmihalyi and Rathunde 1998; Rathunde and Csikszentmihalyi 2006), one marked by integrated and mutually reinforcing contributions to self (e.g., maintaining one's health and one's ability therefore to remain an active agent in one's own development) and to family, community, and the institutions of civil society (e.g., families, neighborhoods, schools, religious groups; Elshtain 1999; Lerner 2004). The contributing person keeps herself healthy and fit, so as not to be an unnecessary liability to or an unnecessary user of the resources of others and, as well, helps family members without any coercion, assists neighbors without any compensation to do so, and helps maintain the institutions of civil society strong by, for instance, volunteering to help others (e.g., through food or clothing drives) and acting to support the institutions of democracy (e.g., by working to enhance voter registration, by supporting political debate, and by voting). An adult engaging in such integrated contributions is a person manifesting adaptive developmental regulations (Brandtstädter 2006).

A second subsidiary hypothesis to the one postulating the Five Cs is that there should be an inverse relation across development between PYD (for example, the Five Cs) and behaviors indicative of risk taking or of internalizing and externalizing problems (for example, delinquency, substance use, depression, aggression, etc.). That is, this hypothesis suggests that as evidence for positive behavior increases there should be fewer indications of problematic behaviors. Simply, the idea is that increases in good things are associated with decreases in what is bad.

This idea was forwarded in particular by Pittman and her colleagues (e.g., Pittman et al. 2001) in regard to applications of developmental science to policies and programs. In essence, the hypothesis is that the best means to prevent problems associated with adolescent behavior and development (e.g., depression, aggression, drug use and abuse, or unsafe sexual behavior) is to promote positive development.

\section{Hypothesis 2. Youth-Context Alignment Promotes PYD}

Based on the idea that the potential for systematic intraindividual change across life (i.e., for plasticity) represents 
a fundamental strength of human development, the hypothesis was generated that, if the strengths of youth (e.g., as represented by the S, O, and $\mathrm{C}$ components of intentional self regulation; Freund and Baltes 2002; Gestsdóttir and Lerner 2008) are aligned with resources for healthy growth present in the key contexts of adolescent development - the home, the school, and the communitythen enhancements in positive functioning at any one point in time (i.e., well-being; Lerner 2004) will be more likely to occur; in turn, the systematic promotion of positive development (i.e., thriving; e.g., Lerner 2004; Lerner et al. 2005a, b) will occur across time. A key subsidiary hypothesis is that there exist, across the key settings of youth development (i.e., families, schools, and communities) "developmental assets" (Benson et al. 2006), that is, features of the ecology of human development that support the growth of a healthy youth.

These positive development-promoting resources may take many forms (Theokas and Lerner 2006; Urban et al. 2009), e.g., they may involve people (e.g., coaches or mentors), programs (e.g., out-of-school-time [OST] activities provided by community-based organizations, such as scouting, 4-H, Boys \& Girls Clubs, YMCA, or Big Brothers/Big Sisters), or features of the natural or designed physical ecology (e.g., parks, playgrounds, or libraries). However, whatever their form, there is broad agreement among researchers and practitioners in the youth development field that the concept of developmental assets is important for understanding what needs to be marshaled in homes, classrooms, and community-based programs to foster PYD (Benson et al. 2006; Lerner 2007).

In fact, a key impetus for the interest in the PYD perspective among both researchers and youth program practitioners and, thus a basis for the collaborations that exist among members of these two communities, lies in ascertaining the nature of the resources for positive development that are present in youth programs, for example, in the literally hundreds of thousands of OST programs delivered either by large, national organizations, such as 4-H or Boys and Girls Clubs, or by local organizations.

The focus on youth programs is important not only for practitioners in the field of youth development, however. In addition, the interest in exploring youth development programs as a source of developmental assets for youth derives from theoretical interest in the role of the macro level systems effects of the ecology of human development on the course of healthy change in adolescence (Bronfenbrenner and Morris 2006); interest derives as well from policy makers and advocates, who believe that at this point in the history of the United States community-level efforts are needed to promote positive development among youth (e.g., Cummings 2003; Gore 2003; Pittman et al. 2001).
Summary of the PYD Perspective

The developmental systems theory-based conception of PYD presents a individual $\leftarrow \rightarrow$ context process model of thriving. This model posits that when there is an alignment across the adolescent period between the strengths of youth (e.g., self-regulation skills, as may be represented by selection, optimization, and compensation; Gestsdóttir and Lerner 2008) and the developmental assets present in the ecology of youth (e.g., resources such as other people or OST programs), then positive youth development-the Five Cs-will develop. In turn, when PYD develops, youth-engaged in adaptive developmental regulations with their context-should manifest contributions to the context that possesses the ecological assets needed for thriving and that, as such, supports PYD. As well, because they are adaptively engaged with their context, PYD should be inversely related to risk or problem behaviors.

The 4-H Study of PYD was designed to test this individual $\leftarrow \rightarrow$ context model of thriving (e.g., Lerner et al. $2005 a, b)$. Figure 1 presents the structural model summarized above and, as such, the model framing the research conducted within the 4-H Study. In addition, the figure includes examples of the indicators of the latent variables included in the structural model. The indicators in the figure are among those involved in the tests of the structural model using the 4-H Study data set. These tests involve both past research using this data set and, as well, the tests found in the empirical articles included in this special issue. Accordingly, we will review past and current tests of the model presented in Fig. 1, emphasizing the contributions of the research within this special issue. To place these tests in their appropriate empirical context it is useful to provide first an overview of the methodology of the 4-H Study.

\section{The 4-H Study of Positive Youth Development}

The 4-H Study was designed to test the idea that when the strengths of youth are aligned across adolescence with family, school, and community resources (and, in particular, resources provided by community-based, out-of-school time youth development programs, such as 4-H, Boys \& Girls Clubs, Big Brothers/Big Sisters, YMCA, and scouting), positive youth development (operationalized by the "Five Cs" of competence, confidence, character, connection, and caring) and, as well, youth community Contributions (the "sixth C" of PYD) will occur (Lerner 2004, 2007; Lerner et al. 2005a, b). The full details of the method of the 4-H Study have appeared in numerous developmental journals across the last 5 years (e.g., Alberts et al. 2006; Bobek et al. 2009; Gestsdóttir and Lerner 2007a, b; 


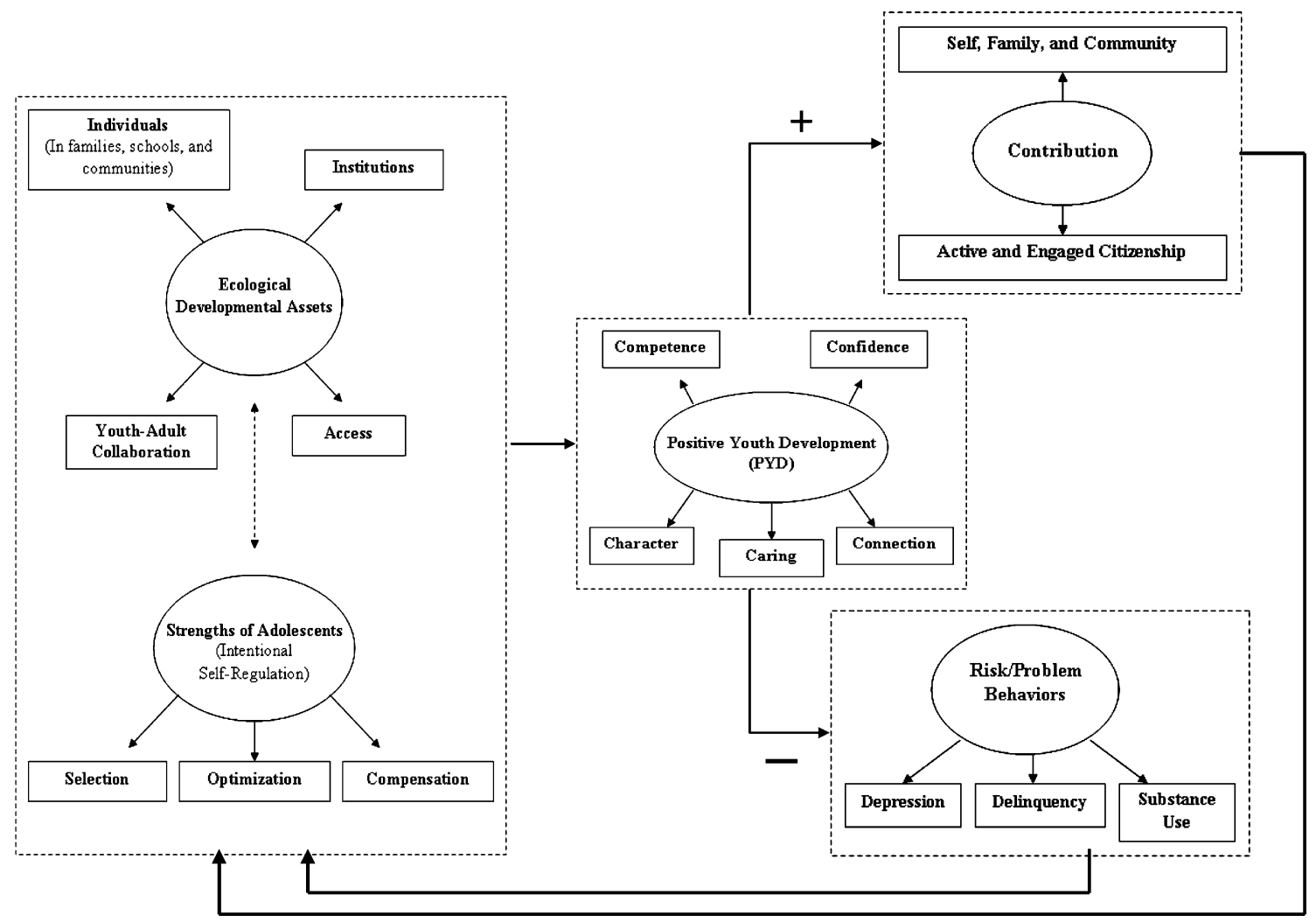

Fig. 1 A developmental systems theory-based model of thriving in adolescence

Gestsdóttir et al. 2009; Jeličić et al. 2007; Lerner et al. 2005a, b; Lewin-Bizan et al. in press; Ma et al. 2009; Phelps et al. 2007, 2009; Theokas and Lerner 2006; Urban et al. 2009; Zarrett et al. 2009; Zimmerman et al. 2007, 2008). Accordingly, we provide here only a summary of the overall method and measurement model of the study, focusing on the information needed to explain the tests of the model presented in Fig. 1.

\section{Design and Sample}

Supported by grants from the National 4-H Council, the 4-H Study of PYD began in 2002 with a sample of about 1,700 5th grade youth and about 1,100 parents from 13 states in the United States. The study uses a form of cohort sequential longitudinal design (Baltes et al. 1977; Collins 2006) and, as such, the sample size increases across successive waves of testing. That is, data from fifth graders were gathered in Wave 1 of the study (the 2002-2003 school year), and these fifth graders were the initial cohort in the study. However, to maintain at least initial levels of power for within-time analyses and to assess the effects of retesting, subsequent waves of the study involved the addition of a "retest control" cohort of youth (and a sample of their parents). Participants in the added "retest control" cohort were then followed longitudinally. In Wave 2, the grade level of the initial cohort was Grade 6. As such, a "retest control" group of sixth graders was added to the study, and these youth became members of the second longitudinal cohort, Cohort 2. Both the original cohort of fifth graders and the added cohort of sixth graders were followed into Grade 7, where in addition to retesting initial Grade 5 and initial Grade 6 participants, a new cohort of seventh graders was added to the sample (along with a sample of their parents). In subsequent waves of testing this process was followed.

At this writing, with the beginning collection of Grade 12 data, the 4-H study includes more than 6,000 youth (about half of whom have been assessed two or more times) and about 3,000 parents from 43 states. Participants reside in rural, suburban, and urban areas in different parts of the country and represent a diverse variety of racial, ethnic, and religious backgrounds and a range of socioeconomic levels. The number of repeated assessments of the participants makes the design especially sensitive to the detection of trajectories of intraindividual change in the structure and function of PYD.

The data set affords a unique opportunity to assess the nature, bases, and import of the development of thriving in adolescence with more waves of data than available in any other data set pertinent to this domain of adolescent development. Accordingly, framed by the structural model 
presented in Fig. 1, we summarize here past research using the 4-H Study data set that is pertinent to tests of the two main (and associated subsidiary) hypotheses of the PYD perspective. In addition, we note how the research reported in this special issue extends past research to further elucidate the meaning and measurement of thriving across the adolescent period.

\section{The Status of Empirical Support for Hypothesis 1}

Findings from the 4-H Study provide some support for the ideas associated with Hypothesis 1 of the PYD perspective, that is, that the "Five Cs," of Competence, Confidence, Connection, Character, and Caring, constitute the structure of PYD. Using data from the first wave (Grade 5) of the study, Lerner et al. 2005b found evidence for a secondorder latent construct of PYD, which consisted of five-firstorder latent constructs, each representing one of the Five Cs. More recently, Phelps et al. (2009) extended Lerner et al. 2005b Grade 5 findings by assessing the structure and development of PYD from Grade 5 to Grade 7 of the 4-H Study. The results indicated that the "Five Cs" Model of PYD continued to be a robust construct that can be defined comparably in Grades 6 and 7 as it was in Grade 5.

Within the present special issue, Bowers et al. extend these findings by examining whether the PYD construct as identified in earlier work had satisfactory psychometric properties for longitudinal measurement invariance across Grades 8-10. That is, Bowers et al. (this issue) asked whether the structure of PYD in middle adolescence was comparable to the structure of this construct present across the early years of this period. Using a hierarchy of secondorder confirmatory factor analysis models to address this issue, the authors found that the scales relevant to measuring the Five Cs were slightly different for two of the Cs during middle adolescence than for early adolescence: Athletic competence was no longer a relevant indicator of Competence; however, physical appearance significantly loaded on the latent construct of Confidence. With this revised model of the "Five Cs," these analyses also found evidence for strict measurement invariance across three measurement occasions, including equivalence of firstorder and second-order factor loadings, equality of intercepts of observed variables, and equality of item uniqueness and disturbances of the first-order factors. Thus, the structural definition of PYD, as illustrated in Fig. 1, has now been confirmed within the 4-H Study data set from the beginning of the adolescent period through the middle portion of this time of life.

Support exists as well for the subsidiary expectations associated with Hypothesis 1. That is, and as also illustrated in the figure, the PYD perspective includes the idea that PYD is linked positively to youth Contribution and negatively to risk and problem behaviors. In an initial test of this idea, Jeličić et al. (2007) found that PYD measured in Grade 5 positive predicted Grade 6 youth Contribution and negatively predicted risk/problems behaviors in this same grade.

However, more recent research using the 4-H data set suggests that the links between PYD, Contribution, and risk/problem behaviors may be more complicated than was envisioned in the initial PYD hypothesis, at least as it has been formulated in the genesis of this perspective. On the one hand, research by Zaff et al. (this issue) suggest that in middle adolescence Contribution itself may become a construct different than the one that is manifested in early adolescence (e.g., as studied by Jeličić et al. 2007). That is, Zaff et al. propose that because of cognitive, socioemotional, and behavioral changes in middle adolescence, the "Contribution" of the early adolescent becomes transformed into an integrated construct of civic engagementActive and Engaged Citizenship (AEC).

Using data from Grades 8-10 of the 4-H Study, Zaff et al. assessed the structure and measurement invariance of AEC, indexed as a second-order latent construct that encompasses four-first-order latent constructs: Civic Duty, Civic Skills, Neighborhood Social Connection, and Civic Participation. Zaff et al. tested measurement invariance between boys and girls and, as well, assessed longitudinal factorial invariance across Grades 8 to Grade 10. Their results supported strong invariance of the AEC between sex, as well as over time, thus indicating that in future tests of the PYD-Contribution relationship the operationalization of contribution must take into consideration the ontogenetically changing meaning of this construct. Simply, although the index of PYD seems to remain invariant across the early-through-middle adolescent period, at least one construct expected to drive from PYD-Contribution-shows developmental transformation.

On the other hand, the link between PYD and risk/ problem behaviors may not be as straightforward as specified in the original formulation of Hypothesis 1 of the PYD perspective. For example, in an assessment of fifth through seventh graders participating in the 4-H Study, Phelps et al. (2007) found that PYD and risk/problem behaviors follow different trajectories over time; that is, the patterns of change associated with these outcomes differ among individuals. Whereas some youth show inverse relations between trajectories of PYD and risk/problem behaviors, other youth show increases in both dimensions and still others show decreases in both. For instance, even among 5th-7th grader youth who have a history of risk/ problem behaviors, including bullying, delinquency, or substance use, there may be substantial evidence of PYD and, as well, Contribution. Accordingly, there may be strengths — and the basis for positive change-among even 
those youth who show trajectories of marked risk/problem behaviors. In turn, even some youth who show developmental trajectories at the highest levels of PYD and Contribution manifest as well high or increasing levels of either internalizing or externalizing behaviors. As such, there may be problems associated with the development of adolescents who manifest even the most positive instances of PYD and Contribution across the early adolescent years.

Similar complexity in middle adolescence seems to exist as well. In the present special issue, Lewin-Bizan et al. (this issue) assessed intraindividual change in positive and problematic indicators across Grades 5-10, and the links between these trajectories of development. Results from person-centered analyses indicated that most youth clustered in the high trajectories of positive indicators and in the low trajectories of the negative ones. However, consistent with the findings of Phelps et al. (2007), which pertained only to youth in Grades 5-7, the Lewin-Bizan et al. findings indicated that positive and problematic trajectories may covary positively, i.e., youth in highly positive PYD trajectories may be the same youth in high problematic trajectories. These results, which extend across the early-through-middle period of adolescence, suggest that, once again, the initial hypothesis of the PYD perspective needs to accommodate to the presence of empirical variations in the links between positive and problematic developmental trajectories among adolescents.

\section{The Status of Empirical Support for Hypothesis 2}

Hypothesis 2 of the PYD perspective indicates that, if the strengths of youth are aligned with developmental assets in the ecology of youth, then youth will be likely to thrive. A key subsidiary hypothesis is that developmental assets exist across the key settings of youth development, i.e., families, schools, and communities (Benson et al. 2006).

Findings from the 4-H Study provide evidence consistent with the ideas of Hypothesis 2, in that they illuminate the nature of both youth strengths and ecological assets and, as well, the links of these individual and contextual variables to PYD and youth Contribution. In a series of studies (Gestsdóttir and Lerner 2007a, b; Gestsdóttir et al. 2009; Zimmerman et al. 2007, 2008), youth strengths, as instantiated by intentional self-regulation skills, and indexed by a measure of Selection (S), Optimization (O) and Compensation (C) (Freund and Baltes 2002), were linked positively within and across the early adolescent through middle adolescent years (Grades 5-10) with PYD and Contribution; in turn, SOC scores were linked negatively to risk/problem behaviors across this portion of adolescence.

In the present special issue, Gestsdóttir et al. extend this research in an important way, one that recognizes (as does the Zaff et al. paper in this special issue) that development involves transformation in the meaning and measurement of characteristics of the person and the context. Gestsdóttir et al. (this issue) note that intentional self regulation describes how people make choices, plan actions to reach their goals, and regulate the execution of their actions, making processes of intentional self regulation central to healthy human functioning. Prior research has confirmed the presence of three processes of intentional self regulation-those depicted by the constructs of $\mathrm{S}, \mathrm{O}$, and $\mathrm{C}$-in middle adolescence (Grades 8 through 10) and has found both predicted, concurrent and across-time, relations to measures of PYD. However, developmental changes and contextual opportunities suggest that a fourth process, Loss Based Selection (LBS), should also develop in middle adolescence and become increasingly important for healthy functioning in later adolescence and in adulthood. Using data from Grade 10 of the 4-H Study, the authors confirm the presence of this fourth structure of intentional self regulation and, as well, provide data validating its use, i.e., LBS in Grade 10 covaries in expected ways with indicators of positive and problematic development.

Other data derived from the 4-H Study identify and elucidate the nature of the ecological developmental assets suggested by Hypothesis 2 to be present in the contexts of youth and, as such, to promote their positive development. For example, Theokas and Lerner (2006) identified four domains of ecological assets in the families, schools, and communities of fifth grade youth within the 4-H Study. These assets involve, first, individuals in the lives of youth-parents, teachers, and community mentors, for instance. The second domain of ecological assets is the physical and institutional resources present in the social environment (these assets index opportunities for learning, recreation, and engagement with individuals and the physical world around oneself and, as well, for providing routines and structure for youth). The third domain of assets is collective activity. This asset domain indexes mutual engagement between community members, parents, youth, school personnel, and institutions of society. The fourth domain is accessibility, an asset that indexes the ability of youth to partake of human resources and resource opportunities in the context. Theokas and Lerner (2006) found that the scores for these four domains of developmental assets were significantly related to both positive and problematic outcomes in expected directions.

In turn, Urban et al. (2009) extended the fifth grade findings of Theokas and Lerner (2006) in an assessment of whether neighborhood assets present for 4-H Study participants across Grades 5-7 moderated the effect of adolescent involvement in out-of-school activities on positive and negative developmental outcomes. The results revealed a complex interplay between individual level factors, 
activity involvement, and neighborhood assets. Activity involvement differentially affected youth outcomes depending upon the ecological context in which they were embedded. For example, activity involvement had the greatest influence on youth living in neighborhoods with limited physical resources. In addition, boys and girls were affected differently by both the amount of time spent in activities and the types of neighborhood supports available. Youth living in lower asset neighborhoods benefited more than their counterparts living in high asset neighborhoods from participation in activities when looking at outcomes of dysfunction. Once again, then, data from the 4-H Study suggest that a more nuanced understanding of personcontext relations is needed to fully capture the range of relations between youth and contexts that are involved in PYD.

Findings by Urban et al. in the present special issue underscore the need for a more nuanced approach to the meaning and measurement of thriving by empirically demonstrating the complex interplay between individual and context that may underlie the adaptive developmental regulations promoting positive development. Again using data from Grades 5-7, Urban et al. (this issue) explored how the intentional self-regulation ability of youth interacted with participation in OST activities to affect PYD among adolescents living in neighborhoods with lower ecological assets. Among girls, high self regulation was linked to benefiting most from involvement in extracurricular activities, as compared to peers with lower self-regulation. For boys, there were fewer significant relationships found between self regulation, activity involvement, and positive development, depression, and risk behaviors. Consistent with a developmental systems perspective, findings from this study affirmed the importance of the relationship between an individual and his/or context, including the impact of distal factors, such as the neighborhood, on youth development.

The research undertaken with the 4-H Study data set has expanded to include the assessment of how other constructs that link individual and context may relate to the course of PYD. One such construct is school engagement. Li, Lerner, and Lerner (this issue) note that school engagement is a person $\leftarrow \rightarrow$ context relational construct that depicts the way in which the individual cognitively, emotionally, and behaviorally interacts with the school setting and, as such, they suggest that school engagement may mediate the associations between ecological and personal assets and academic competence. This idea was examined through the use of data from Grades 5 and 6 of the 4-H Study. Using latent variable structural equation modeling, evidence was found in support of the presence of two distinct school engagement components, Behavioral and Emotional, and for the role of these facets of school engagement in the relations between developmental assets and later academic competence. Personal and ecological assets had indirect effects on later academic competence, via behavioral and emotional school engagement. Behavioral and emotional school engagement predicted academic competence differently. Emotional engagement was indirectly linked to academic competence, via the role of behavioral engagement. Behavioral and emotional engagement also and had different individual and contextual antecedents.

Although not a direct test of the two core hypotheses involved in the PYD perspective, a final paper included in the special issue is important for helping the scholarly community understand the methodological limitations of the research we report and, indeed, for understanding all developmental research pertinent to adolescence. That is, Jeličić et al. (this issue) study the presence and treatment of missing data, a methodological issue complicating the analysis and interpretation of the findings from virtually all longitudinal studies of human development.

Methods to treat missing data that have been recommended across the past two decades are well described in the literature, but most of these procedures focus on missing data from cross-sectional studies. The majority of simulation studies show that different missing data procedures can impact cross-sectional results and there are only a few such studies that examined this impact on longitudinal data. However, there are no empirical examples using actual longitudinal data sets that show the extent to which different missing data procedures can yield different results. Data from the first three waves of the 4-H Study of Positive Youth Development were used to provide such an illustration. The results showed that the three missing data techniques, i.e., listwise deletion, maximum likelihood (ML) and multiple imputation (MI), did not yield comparable results for research questions assessing different aspects of development (i.e., change over time or prediction effects). The results indicated also that listwise deletion should not be used. Instead, both the ML and the MI methods should be used to determine if and how results change when these procedures are employed.

The cautions about the analysis of, and generalizations drawn from, data derived from longitudinal studies of adolescence, in general, and from longitudinal investigations of thriving among youth, in particular, are important not only for the conduct of good science. In addition, as evidenced by the two commentaries included in this special issue, precision in the conduct of research about PYD and caution about the inferences we draw from our data are needed because youth serving professionals (Floyd, this issue) and policy makers (Porter, this issue) increasingly rely on the results of the genre of research included in this special issue to frame their efforts to enhance the lives of diverse youth across the United States and internationally. 
Because of this potentially profound and broad impact, developmental researchers have both a special obligation and a unique opportunity to apply their science to foster thriving among, literally, millions of youth.

\section{Conclusions}

Thirty years ago at this writing, Lipsitz (1977) riveted the attention of the developmental science community by noting that adolescents, and particularly youth in the early portion of this period, were "growing up forgotten." Lipsitz explained that neither researchers nor practitioners (and, arguably, especially policy makers) were attending sufficiently to the nature of development during much of the second decade of life and, as such, the challenges, strengths, and opportunities for applications (programs or policies) of this portion of the life span were either ignored or abandoned to the largely empirically unsubstantiated idea that inevitable storm and stress-problems and deficits of character and behavior-were prototypic features of youth development.

Lipsitz's work elicited increased scrutiny of available theory and research about adolescence and, across the 1980s, the lens of developmental science included not only evaluation of whether extant knowledge of adolescent development justified the idea that the adolescents were "problems to be managed" (Roth and Brooks-Gunn 2003a, b) but, as well, a burgeoning of research attention to the second decade of life and, as such, the emergence of the study of adolescence as a separate and valued field of developmental inquiry, one that was commensurate in status to the study of earlier and later portions of the life span (Lerner and Steinberg 2004, 2009; Steinberg and Lerner 2004).

When, in the 1990s, the hegemony of the deficit model of adolescence began to give way to the combined influence of the growing prominence of developmental systems theories, to the idea of plasticity deriving from such theories, and to the burgeoning of the strengths-based, PYD perspective, adolescence was no longer a forgotten portion of the life span or one "reflexively" regarded as an inevitable period of storm and stress (see Lerner and Steinberg 2009; Lerner et al. 2010a, b; Steinberg and Lerner 2004, for reviews of this history). Quite to the contrary, the research that today is the focus of much of the scholarship about the second decade of life is characterized by an optimistic view about the potentials of youth for healthy and positive development across adolescence.

Moreover, this focus on the description, explanation, and potential optimization of thriving across adolescence has drawn the attention of scholars interested in promoting both the successful transition to and positive development across the adult years (e.g., see Baltes et al. 2006; Lamb and Freund 2010; Overton 2010a). In short, as an impetus to researchers, practitioners, policy makers concerned with promoting positive development within adolescence, and to scholars of life-span development as well, the study of the meaning and measurement of thriving across the adolescent period is, and will likely continue to be, an area of prominent research importance.

The research and commentaries included in this special issue document the conceptual usefulness and empirical strength of the developmental systems theory-based, PYD perspective. In addition, the scholarship included in this special issue reinforces prior research derived from the 4-H Study data set that suggests that the ideas associated with the original formulation of the PYD perspective need to evolve, to become more nuanced, and to focus more on what seem to be quite diverse and intricately linked pathways of thriving and of risk/problem behaviors. The research reported in this special issue points to some instances of where such conceptual, and associated empirical, revisions, may need to be focused. As research derived from the 4-H Study continues to be generated about these, and probably to-be-discovered, areas of needed refinement, and as other data sets are used to explore the bases and implications of thriving across the adolescent years, developmental science will become increasing able to specify what sorts of individual and context resources need to be linked to maximize the probability that all young people will be given a greater chance to thrive. If the work presented in this special issue contributes in some way to this progress, then the efforts of the colleagues involved in the 4-H Study will have been amply rewarded.

Acknowledgments The writing of this article was supported in part by a grant from the National $4-\mathrm{H}$ Council. We are grateful to Erin Phelps for her invaluable contributions to the research reported in this special issue, and to Jarrett M. Lerner, for his masterful editorial skills.

\section{References}

Alberts, A. E., Christiansen, E. D., Chase, P., Naudeau, S., Phelps, E., \& Lerner, R. M. (2006). Qualitative and quantitative assessments of thriving and contribution in early adolescence: Findings from the 4-H Study of Positive Youth Development. Journal of Youth Development, 1(2), 22-34. Retrieved from http://data.memberclicks.com/ site/nae4a/JYD_060102final.pdf.

Baltes, P. B., \& Baltes, M. M. (1990). Psychological perspectives on successful aging: The model of selective optimization with compensation. In P. B. Baltes \& M. M. Baltes (Eds.), Successful aging: Perspectives from the behavioral sciences (pp. 1-34). New York: Cambridge University Press.

Baltes, P. B., Lindenberger, U., \& Staudinger, U. M. (2006). Lifespan theory in developmental psychology. In R. M. Lerner (Ed.), Theoretical models of human development. Volume 1 of handbook of child psychology (6th ed., pp. 569-664). Hoboken, NJ: Wiley. Editors-in-chief: W. Damon \& R. M. Lerner. 
Baltes, P. B., Reese, H. W., \& Nesselroade, J. R. (1977). Life-span developmental psychology: Introduction to research methods. Monterey, CA: Brooks/Cole.

Benson, P. L. (2006). The science of child and adolescent spiritual development: Definitional, theoretical and field-building challenges. In E. C. Roehlkepartain, P. E. King, L. Wagner, \& P. L. Benson (Eds.), The handbook of spiritual development in childhood and adolescence (pp. 484-497). Thousand Oaks, CA: Sage Publications.

Benson, P. L., Scales, P. C., Hamilton, S. F., \& Semsa, A., Jr. (2006). Positive youth development: Theory, research, and applications. In R. M. Lerner (Ed.), Theoretical models of human development. Volume 1 of handbook of child psychology (6th ed.). Hoboken, NJ: Wiley. Editors-in-chief: W. Damon \& R. M. Lerner.

Bobek, D. L., Zaff, J., Li, Y., \& Lerner, R. M. (2009). Cognitive, emotional, and behavioral components of civic action: Towards an integrated measure of civic engagement. Journal of Applied Developmental Psychology, 30(5), 615-627.

Brandtstädter, J. (1998). Action perspectives on human development. In W. Damon (Series Ed.) \& R. M. Lerner (Vol. Ed.), Handbook of child psychology: Vol. 1. Theoretical models of human development (5th ed., pp. 807-863). New York: Wiley.

Brandtstädter, J. (1999). The self in action and development: Cultural, biosocial, and ontogenetic bases of intentional self-development. In J. Brandtstädter \& R. M. Lerner (Eds.), Action and selfdevelopment: Theory and research through the life-span (pp. 3765). Thousand Oaks, CA: Sage.

Brandtstädter, J. (2006). Action perspectives on human development. In R. M. Lerner (Ed.), Handbook of child psychology: Vol. 1. Theoretical models of human development (6th ed.). Hoboken, NJ: Wiley. Editors-in-chief: W. Damon \& R. M. Lerner.

Bronfenbrenner, U., \& Morris, P. A. (2006). The bioecological model of human development. In R. M. Lerner (Ed.), Handbook of child psychology: Vol. 1. Theoretical models of human development (6th ed.). Hoboken, NJ: Wiley. Editors-in-chief: W. Damon \& R. M. Lerner.

Cairns, R. B., \& Cairns, B. D. (2006). The making of developmental psychology. In R. M. Lerner (Ed.), Theoretical models of human development. Volume 1 of handbook of child psychology (6th ed., pp. 89-165). Hoboken, NJ: Wiley. Editors-in-chief: W. Damon \& R. M. Lerner.

Collins, L. M. (2006). Analysis of longitudinal data: The integration of theoretical model, temporal design, and statistical model. Annual Review of Psychology, 57, 505-528.

Csikszentmihalyi, M., \& Rathunde, K. (1998). The development of the person: An experiential perspective on the ontogenesis of psychological complexity. In W. Damon (Series Ed.) \& R. M. Lerner (Ed.), Handbook of child psychology: Vol. 1 Theoretical models of human development (5th Ed., pp. 635-684). New York: Wiley.

Cummings, E. (2003). Foreword. In D. Wertlieb, F. Jacobs, \& R. M. Lerner (Eds.), Promoting positive youth and family development: Community systems, citizenship, and civil society: Vol. 3. Handbook of applied developmental science: Promoting positive child, adolescent, and family development through research, policies, and programs (pp. 9-11). Thousand Oaks, CA: Sage.

Damon, W. (2004). What is positive youth development? The Annals of the American Academy of Political and Social Science, 591, $13-24$.

DuBois, D. L., \& Rhodes, J. E. (2006). Youth mentoring: Bridging science with practice. Journal of Community Psychology, 34, $547-565$.

Eccles, J. S., \& Gootman, J. A. (Eds.). (2002). Community programs to promote youth development/committee on community-level programs for youth. Washington DC: National Academy Press.
Elshtain, J. B. (1999). A call to society. Society, 36(5), 11-19.

Floyd, D. T., \& McKenna, L. (2003). National youth serving organizations in the United States: Contributions to civil society. In R. M. Lerner, F. Jacobs, \& D. Wertlieb (Eds.), Handbook of applied developmental science: Promoting positive child, adolescent, and family development through research, policies, and programs: Vol. 3. Promoting positive youth and family development: Community systems, citizenship, and civil society (pp. 11-26). Thousand Oaks, CA: Sage Publications.

Freund, A. M., \& Baltes, P. B. (2002). Life-management strategies of selection, optimization and compensation: Measurement by selfreport and construct validity. Journal of Personality and Social Psychology, 82, 642-662.

Gestsdóttir, S., \& Lerner, R. M. (2007a). Hlutverk sjálfstjórnar í æskilegum proska barna og unglinga. Sálfraððiritið, 12, 37-55.

Gestsdóttir, S., \& Lerner, R. M. (2007b). Intentional self-regulation and positive youth development in early adolescence: Findings from the 4-H study of positive youth development. Developmental Psychology, 43(2), 508-521.

Gestsdóttir, G., \& Lerner, R. M. (2008). Positive development in adolescence: The development and role of intentional self regulation. Human Development, 51, 202-224.

Gestsdóttir, S., Lewin-Bizan, S., von Eye, A., Lerner, J. V., \& Lerner, R. M. (2009). The structure and function of selection, optimization, and compensation in middle adolescence: Theoretical and applied implications. Journal of Applied Developmental Psychology, 30(5), 585-600.

Gore, A. (2003). Foreword. In R. M. Lerner \& P. L. Benson (Eds.), Developmental assets and asset-building communities: Implications for research, policy, and practice (pp. 11-12). Norwell, MA: Kluwer.

Gottlieb, G., Wahlsten, D., \& Lickliter, R. (2006). The significance of biology for human development: A developmental psychobiological systems view. In R. M. Lerner (Ed.), Theoretical models of human development. Volume 1 of handbook of child psychology (6th ed.). Hoboken, NJ: Wiley. Editors-in-chief: W. Damon \& R. M. Lerner.

Jeličić, H., Bobek, D., Phelps, E. d., Lerner, J. V., \& Lerner, R. M. (2007). Using positive youth development to predict contribution and risk behaviors in early adolescence: Findings from the first two waves of the 4-H study of positive youth development. International Journal of Behavioral Development, 31(3), 263273.

Karcher, M. J., Davis, C., \& Powell, B. (2002). The effects of developmental mentoring on connectedness and academic achievement. School Community Journal, 12(2), 35-50.

King, P. E., Dowling, E. M., Mueller, R. A., White, K., Schultz, W., Osborn, P., et al. (2005). Thriving in adolescence: The voices of youth-serving practitioners, parents, and early and late adolescents. Journal of Early Adolescence, 25(1), 94-112.

Lamb, M. E., \& Freund, A. M. (Eds.). (2010). Social and emotional development. Volume 2 of the handbook of lifespan development. Hoboken, NJ: Wiley. R. M. Lerner, Editor-in-Chief.

Larson, R. W. (2000). Toward a psychology of positive youth development. American Psychologist, 55(1), 170-183.

Lerner, R. M. (1978). Nature, nurture, and dynamic interactionism. Human Development, 21, 1-20.

Lerner, R. M. (1984). On the nature of human plasticity. New York: Cambridge University Press.

Lerner, R. M. (2002). Concepts and theories of human development (3rd ed.). Mahwah, NJ: Lawrence Erlbaum Associates.

Lerner, R. M. (2004). Liberty: Thriving and civic engagement among American youth. Thousand Oaks, CA: Sage.

Lerner, R. M. (2005). Promoting Positive Youth Development: Theoretical and Empirical Bases. White paper prepared for the Workshop on the Science of Adolescent Health and 
Development, National Research Council/Institute of Medicine., September. Washington, DC: National Academies of Science.

Lerner, R. M. (2006). Developmental science, developmental systems, and contemporary theories. In R. M. Lerner (Ed.), Theoretical models of human development. Volume 1 of handbook of child psychology (6th ed.). Hoboken, NJ: Wiley. Editorsin-chief: W. Damon \& R. M. Lerner.

Lerner, R. M. (2007). The good teen: Rescuing adolescents from the myths of the storm and stress years. New York, NY: The Crown Publishing Group.

Lerner, R. M. (2009). The positive youth development perspective: Theoretical and empirical bases of a strength-based approach to adolescent development. In C. R. Snyder \& S. J. Lopez (Eds.), Oxford handbook of positive psychology (2nd ed., pp. 149-163). Oxford, England: Oxford University Press.

Lerner, R. M., Alberts, A. E., \& Bobek, D. (2007). Thriving youth, flourishing civil society-How positive youth development strengthens democracy and social justice. In Bertelsmann. Stiftung (Ed.), Civic engagement as an educational goal (pp. 21-35). Guterslöh, Germany: Verlag Bertelsmann Stiftung.

Lerner, R. M., Boyd, M. J., Kiely, M. K., Napolitano, C. M., Schmid, K. L., \& Steinberg, L. (2010a). The history of adolescence. In B. Brown \& M. Prinstein (Eds.), Encyclopedia of Adolescence. Oxford, England: Elsevier.

Lerner, R. M., \& Lerner, J. V., Almerigi, J., \& Theokas, C. (Eds.). (2005a). Positive youth development. Journal of Early Adolescence, 25(1), 1-144.

Lerner, R. M., Lerner, J. V., Almerigi, J., Theokas, C., Phelps, E., Gestsdóttir, S., et al. (2005b). Positive youth development, participation in community youth development programs, and community contributions of fifth grade adolescents: Findings from the first wave of the 4-H study of positive youth development. Journal of Early Adolescence, 25(1), 17-71.

Lerner, J. V., Phelps, E., Forman, Y., \& Bowers, E. P. (2009a). Positive youth development. In R. M. Lerner \& L. Steinberg (Eds.), Handbook of adolescent psychology: Vol. 1. Individual bases of adolescent development (3rd ed., pp. 524-558). Hoboken, NJ: Wiley.

Lerner, R. M., \& Steinberg, L. (Eds.). (2004). Handbook of adolescent psychology (2nd ed.). Hoboken, NJ: Wiley.

Lerner, R. M., \& Steinberg, L. (Eds.). (2009). Handbook of adolescent psychology (3rd ed.). Hoboken, NJ: Wiley.

Lerner, R. M., von Eye, A., Lerner, J. V., \& Lewin-Bizan, S. (2009b). Exploring the foundations and functions of adolescent thriving within the 4-H study of positive youth development: A view of the issues. Journal of Applied Developmental Psychology, 30(5), $567-570$

Lerner, R. M., Wiatrowski, M., Kiely, M. K., Napolitano, C., Schmid, K. L., \& Prichard, A. (2010b). A vision for the American juvenile justice system: The positive youth development perspective. In F. Sherman \& F. Jacobs (Eds.), Health and wellbeing in the juvenile justice system: Youth in context. Hoboken, NJ: Wiley.

Lewin-Bizan, S., Bowers, E., \& Lerner, R. M. (in press). One good thing leads to another: Cascades of positive youth development among American adolescents. Development and Psychopathology.

Lipsitz, J. (1977). Growing up forgotten: A review of research and programs concerning early adolescence. Lexington, MA: Lexington Books.

Ma, L., Phelps, E., Lerner, J. V., \& Lerner, R. M. (2009). The development of academic competence among adolescents who bully and who are bullied. Journal of Applied Developmental Psychology, 30(5), 628-644.

Novikoff, A. B. (1945a). The concept of integrative levels and biology. Science, 101, 209-215.
Novikoff, A. B. (1945b). Continuity and discontinuity in evolution. Science, 101, 405-406.

Overton, W. F. (1973). On the assumptive base of the nature-nurture controversy: Additive versus interactive conceptions. Human Development, 16, 74-89.

Overton, W. F. (2006). Developmental psychology: Philosophy, concepts, methodology. In R. M. Lerner \& W. Damon (Eds.), Handbook of child psychology: Vol. 1. Theoretical models of human development (6th ed., pp. 18-88). Hoboken, NJ: Wiley.

Overton, W. F. (Ed.). (2010a). Cognition, biology, and methods. Volume 1 of the handbook of life-span development. Hoboken, NJ: Wiley. Editor-in-Chief: R. M. Lerner.

Overton, W. F. (2010b). Life-span development: Concepts and issues. In W. F. Overton (Ed.), Cognition, biology, and methods. Volume 1 of the handbook of life-span development. Hoboken, NJ: Wiley. Editor-in-chief: R. M. Lerner.

Phelps, E., Balsano, A., Fay, K., Peltz, J., Zimmerman, S., Lerner, R. M., et al. (2007). Nuances in early adolescent development trajectories of positive and of problematic/risk behaviors: Findings from the 4-H study of positive youth development. Child and Adolescent Clinics of North America, 16(2), 473-496.

Phelps, E., Zimmerman, S., Warren, A. E. A., Jeličić, H., von Eye, A., \& Lerner, R. M. (2009). The structure and developmental course of positive youth development (PYD) in early adolescence: Implications for theory and practice. Journal of Applied Developmental Psychology, 30(5), 571-584.

Pittman, K., Irby, M., \& Ferber, T. (2001). Unfinished business: Further reflections on a decade of promoting youth development. In Public/Private Ventures (Ed.), Youth development: Issues, challenges, and directions (pp. 17-64). Philadelphia: Public/Private Ventures.

Rathunde, K., \& Csikszentmihalyi, M. (2006). The developing person: An experiential perspective. In R. M. Lerner \& W. Damon (Eds.), Handbook of child psychology (6th ed., pp. 465-515). Hoboken, NJ: Wiley.

Rhodes, J. E., \& Lowe, S. R. (2009). Mentoring in adolescence. In R. M. Lerner \& L. Steinberg (Eds.), Handbook of adolescent psychology: Vol. 2. Contextual influences on adolescent development (3rd ed., pp. 152-190). Hoboken, NJ: Wiley.

Roth, J. L., \& Brooks-Gunn, J. (2003a). What is a youth development program? Identification and defining principles. In F. Jacobs, D. Wertlieb, \& R. M. Lerner (Eds.). Enhancing the life chances of youth and families: public service systems and public policy perspectives. Volume 2 of handbook of applied developmental science: promoting positive child, adolescent, and family development through research, policies, and programs (pp. 197-223). Thousand Oaks, CA: Sage Publications.

Roth, J. L., \& Brooks-Gunn, J. (2003b). What exactly is a youth development program? Answers Roth, J. L., \& Brooks-Gunn, J. (2003). What exactly is a youth development program? Answers from research and practice. Applied Developmental Science, 7, 94-111.

Schneirla, T. C. (1957). The concept of development in comparative psychology. In D. B. Harris (Ed.), The concept of development: An issue in the study of human behavior (pp. 78-108). Minneapolis, MN: University of Minnesota Press.

Silbereisen, R. K., \& Lerner, R. M. (2007). Approaches to positive youth development: A view of the issues. In R. K. Silbereisen \& R. M. Lerner (Eds.), Approaches to positive youth development (pp. 3-30). London: Sage Publications.

Steinberg, L., \& Lerner, R. M. (2004). The scientific study of adolescence: A brief history. Journal of Early Adolescence, 24(1), 45-54.

Theokas, C., \& Lerner, R. M. (2006). Observed ecological assets in families, schools, and neighborhoods: Conceptualization, 
measurement, and relations with positive and negative developmental outcomes. Applied Developmental Science, 10(2), 61-74.

Tobach, E., \& Greenberg, G. (1984). The significance of T. C. Schneirla's contribution to the concept of levels of integration. In G. Greenberg \& E. Tobach (Eds.), Behavioral evolution and integrative levels. Hillsdale, NJ: Erlbaum.

Tobach, E., \& Schneirla, T. C. (1968). The biopsychology of social behavior of animals. In R. E. Cooke \& S. Levin (Eds.), Biologic basis of pediatric practice (pp. 68-82). New York: McGrawHill.

Urban, J. B., Lewin-Bizan, S., \& Lerner, R. M. (2009). The role of neighborhood ecological assets and activity involvement in youth developmental outcomes: Differential impacts of asset poor and asset rich neighborhoods. Journal of Applied Developmental Psychology, 30(5), 601-614.

von Bertalanffy, L. (1933). Modern theories of development. London: Oxford University Press.

Zarrett, N., Fay, K., Carrano, J., Li, Y., Phelps, E., \& Lerner, R. M. (2009). More than child's play: Variable- and pattern-centered approaches for examining effects of sports participation on youth development. Developmental Psychology., 45(2), 368-382.

Zimmerman, S., Phelps, E., \& Lerner, R. M. (2007). Intentional selfregulation in early adolescence: Assessing the structure of selection, optimization, and compensations processes. European Journal of Developmental Science, 1(3), 272-299.

Zimmerman, S., Phelps, E., \& Lerner, R. M. (2008). Positive and negative developmental trajectories in U.S. adolescents: Where the PYD perspective meets the deficit model. Research in Human Development, 5, 153-165.

\section{Author Biographies}

Richard M. Lerner is the Bergstrom Chair in Applied Developmental Science and the Director of the Institute for Applied Research in Youth Development at Tufts University. Lerner has more than 500 scholarly publications, including more than 70 authored or edited books. He was the founding editor of the Journal of Research on
Adolescence and of Applied Developmental Science, which he continues to edit. Lerner is known for his theory of relations between life-span human development and social change, and for his research about the relations between adolescents and their peers, families, schools, and communities. His work integrates the study of public policies and community-based programs with the promotion of positive youth development and youth contributions to civil society.

Alexander von Eye is a professor in the Department of Psychology at Michigan State University. He is a life span developmental scientist and a developmental methodologist. His research includes the study of the interactions among genetics, neuroscience and psychosocial development, health and human development, cognition across the adult years, mother-child interaction, positive youth development, and the use of longitudinal designs to study development.

Jacqueline V. Lerner is a full professor at the Boston College Lynch School of Education. Her current research and teaching interests include the study of positive youth development, the transition to adulthood, temperament and self regulation; early adolescent transitions, and life-span developmental theory. She has been the Scientific Director of the 4-H Study of Positive Youth Development since 2001.

Selva Lewin-Bizan is a postdoctoral fellow at the Institute for Applied Research in Youth Development, Tufts University, working on the 4-H Study of Positive Youth Development. Her research focuses on how contextual assets such as family dynamics and monetary resources affect the lives of youth and parents.

Edmond P. Bowers is a postdoctoral fellow at the Institute for Applied Research in Youth Development at Tufts University. Currently he is Project Director for a grant funded by the Thrive Foundation for Youth of Menlo Park, CA, to develop and test a toolkit to increase the capacity of mentors in youth-serving organizations to assist young people in the growth of goal-management behaviors. His research focuses on the influence of non-parental caregivers on the development of adolescent life skills. 